\title{
TRABAJADORES Y NANOTECNOLOGÍA
}

\author{
Guillermo Foladori \\ Unidad Académica en Estudios del Desarrollo, UAZ \\ gfoladori@gmail.com
}

La nanotecnología es la manipulación de la materia a escala atómica y molecular. Significa combinar artificialmente átomos y moléculas para crear partículas y estructuras que manifiesten funciones nuevas, diferentes a las de la materia en tamaño mayor. Trabajar la materia a una escala tan pequeña representa una revolución tecnológica porque, en dicha escala, los materiales manifiestan propiedades físico-químicas y biológicas (incluyendo toxicológicas) diferentes a las que se muestran en escala mayor. Es como descubrir un mundo nuevo de materiales.

\section{Introducción}

$\mathrm{E}$ $\mathrm{n}$ abril de 2012, la Food and Drug Administration (FDA) de Estados Unidos emitió un Borrador de Guía dirigido a la discusión pública para la regulación de la nanotecnología en alimentos y cosméticos. ${ }^{1}$ En esta guía se alerta sobre varias especificaciones de las nanopartículas incorporadas a los alimentos, sea a los alimentos propiamente dichos, a los colorantes o a los utensilios y envases que entran en contacto con los alimentos. Así, por ejemplo, se reconoce que las nanopartículas pueden migrar del envase al alimento, o que la enzima quimosina preparada a partir de fuentes animales es químicamente diferente de la misma enzima preparada a partir de fuentes microbianas. Se trata de los comienzos de una reglamentación de los alimentos y cosméticos producidos con nanotecnología.

Existen muchos productos en el mercado que son resultado de la nanotecnología. Hay alimentos, cosméticos, electrodomésticos, computadoras, celulares, medicinas, textiles, cerámicas, materiales de construcción, artículos deportivos, armas, entre otros.

En la alimentación, la nanotecnología se aplica en los productos, envases, suplementos alimenticios y en la producción agrícola. Hay más de 200 compañías que investigan y/ o producen en la rama. Se utiliza la nanotecnología en el propio producto, para, por ejemplo, homogeneizar la textura y enfatizar el sabor en cremas y helados, o para reducir el contenido graso, como lo investigan Kraft, Unilever, Nestlé o Blue Pacific Flavors. O, también, para agregarle al producto suplementos alimenticios nanoencapsulados, como Omega3, fortificantes o adelgazantes. También se investiga en alimentos que llevan incorporados cosméticos, como lo hace L'Oréal en asociación con Nestlé o BASF. En los envases, la nanotecnología se utiliza para hacer más durable el producto en los anaqueles de los supermercados, como la cerveza en botella de nanocerámica de la Miller Brewing; o para que la materia prima no se deteriore, como experimenta McDonalds o Mr. Kipling. Las grandes corporaciones químicas de semillas, como Syngenta, Monsanto, Bayer y Dow Chemicals investigan y producen agrotóxicos y semillas nanoencapsuladas.

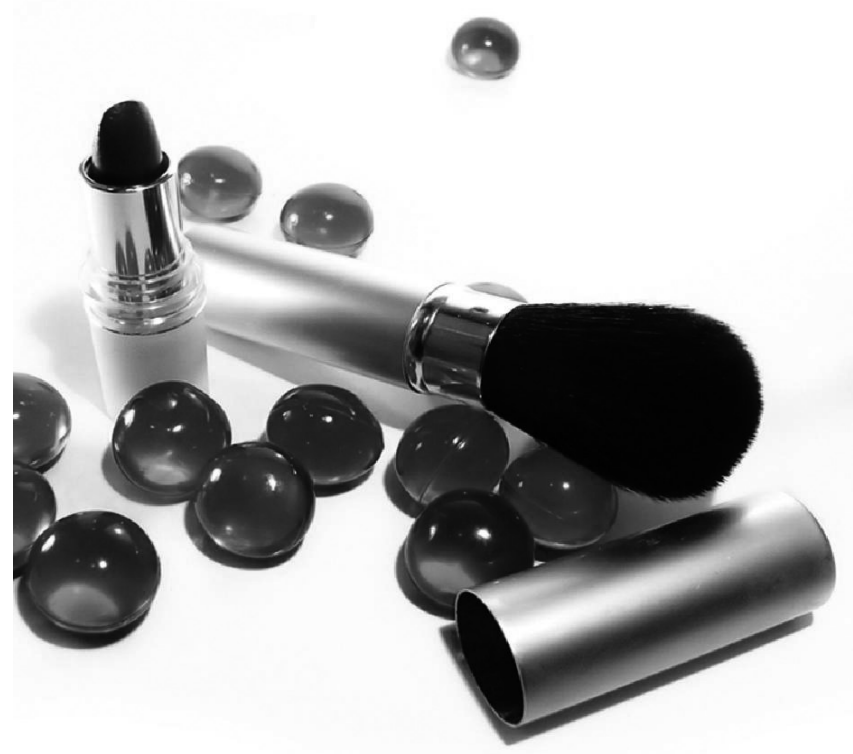

La rama de cosméticos es la que ofrece más productos de la nanotecnología en el mercado. La gran mayoría de las corporaciones transnacionales tienen cremas antiarrugas, filtros solares y shampoo, como Chanel, Clinique, L'Oréal, Revlon, Johnson \& Johnson, Proctor \& Gamble o Lancôme. Aplicada a los filtros solares, la nanoescala hace transparente la crema para evitar el color blanco que tradicionalmente la caracteriza. También se usa la nanotecnología para difundir la luz y ocultar arrugas, y para muchas otras funciones. Hay cepillos de dientes y pasta dentífrica con nanopartículas de plata como bactericida. La Unión Europea está legislando sobre el uso de nanotecnología en cosméticos, dada la gran cantidad de evidencias de los efectos perjudiciales sobre la salud. 
Varios electrodomésticos incluyen nanopartículas de plata como bactericida; es el caso de aires acondicionados, refrigeradores, lavarropas y lavavajillas de Samsung o LG. Filmes de nanotecnología son usados para cubrir pisos, o nanopartículas son incorporadas a pinturas y también a algunos aerosoles para aplicar en muebles y pisos. Los vidrios pueden ser procesados con nanotecnología para evitar que se les adhiera polvo y suciedad y para facilitar el escurrimiento del agua. En los textiles, la aplicación de técnicas nanotecnológicas evita que la ropa se manche y se arrugue.

En algunos casos, se incorporan nanopartículas de plata con efecto bactericida en uniformes médicos o en vestimenta especial para enfermos, pero también en sábanas, toallas y medias. Las medicinas procesadas con nanotecnología prometen ser más eficientes y tener menos efectos colaterales. La nanotecnología está presente en artículos deportivos, en raquetas de tenis, palos de golf, zapatos deportivos, ropa climatizada, etcétera. Las principales marcas de computadoras, celulares y juegos electrónicos almacenan su información en baterías de litio con ánodos recubiertos con nanotecnología, y utilizan nanodispositivos electromecánicos. Automóviles de lujo ya llevan incorporadas más de 30 partes que contienen nanodispositivos o combinan nanopartículas.

La industria de armamento es una de las que más se ha beneficiado de las nanotecnologías, y es también una de las áreas que más se impulsa este tipo investigación; de misiles de precisión a superexplosivos, y de sensores a chalecos antibala, el interés militar está ligado a sus avances.

En el Borrador de Guía para cosméticos de la FDA se dice, entre otras cosas, que los productos deben pasar por un examen toxicológico: "The initial step in the evaluation of the safety assessment of cosmetic products is to conduct toxicity testing based on a toxicological profile of the ingredients and their routes of exposures", cosa que en muchos países de América Latina no sucede con cosméticos que utilizan elementos conocidos por su inocuidad a nivel macro, lo cual no significa que no sean tóxicos a nivel nano.

A una década de fuerte impulso a las nanotecnologías en los países desarrollados y muchos otros, el capítulo de las implicaciones para los trabajadores y consumidores se ha dejado sistemáticamente de lado. Las agendas latinoamericanas ni siquiera mencionan el tema. En Estados Unidos, la National Institute for Occupational Safety and Health (NIOSH), agencia gubernamental encargada de la salud ocupacional, advierte, desde hace más de cinco años, sobre los riesgos de las nanotecnologías en la salud de los trabajadores y, podríamos agregar, en la salud de los consumidores y en el medio ambiente, al tiempo que reclama una actitud más responsable de la Environmental Protection Agency (EPA), que se encarga de regular los productos que entran en el mercado. Como suele ocurrir con cualquier cambio tecnológico, los trabajadores quedan atrás: no reciben los beneficios y sufren los perjuicios.

¿Qué se sabe respecto de los riesgos de las nanotecnologías en los trabajadores? Se sabe que las nanopartículas pueden tener efectos tóxicos, y que hay diferentes grados de exposición.

\section{Se sabe que las nanopartículas pueden tener efectos tóxicos aún cuando el mismo elemento en tamaño mayor no sea tóxico}

El principal riesgo de los productos con nanotecnología es que entran al mercado sin ningún estudio de toxicidad. Tal vez no todas las nanopartículas tengan efectos tóxicos para la salud humana o ambiental. Tal vez sea en determinadas circunstancias que adquieran efectos tóxicos, pero esto no puede ser dirimido si no existen estudios de toxicidad.

$\mathrm{El}$ argumento de científicos, empresarios y gobierno para continuar incentivando el desarrollo de las nanotecnologías y su presencia en el mercado sin estudios de toxicidad previos es que la información existente sobre toxicidad de las nanopartículas en la salud humana aún no es concluyente. Se trata de un argumento parcial e interesado, que explota la novedad del tema sin dar importancia a la salud de trabajadores y consumidores. Si se sitúa la afirmación en el contexto de lo que ya se sabe sobre toxicidad de las nanopartículas, la afirmación es encubridora de potenciales riesgos.

Existe suficiente información como para tener una actitud precautoria, pero ésta no se hace valer porque actualmente se anteponen los intereses del mercado. Esta información puede resumirse como sigue:

Las nanopartículas manufacturadas tienen tamaño, forma y propiedades fisico-químicas y biológicas (toxicológicas) novedosas. Son estas propiedades novedosas las que dan a las nanotecnologías su gran potencial, ya que la materia desarrolla manifestaciones que no son conocidas en tamaño mayor. Si son tratados como materiales nuevos para aplicaciones prácticas, debieran ser tratados con el mismo respeto en términos toxicológicos, realizando estudios sobre los efectos de las nanopartículas en los trabajadores que las manipulan, elaborando guías de manejo obligatorias basadas en el grado de exposición y riesgo, estableciendo canales de información para los trabajadores y evitando lanzar al mercado productos sin previo análisis toxicológico de su ciclo de vida. Como ejemplo de la desconsideración de los impactos sobre la salud, baste decir que, para fines de 2010, los expertos del NIOSH señalaban que no se habían realizado estudios sobre potenciales efectos adversos a la salud en trabajadores que producen nanotubos de carbono o nanofibras, una materia prima que crece exponencialmente en el mercado de nanomaterias primas y que se aplica a muy diversos sectores económicos. ${ }^{2}$ 
Varias nanopartículas han resultado tóxicas en análisis in vitro $y$ en organismos vivos. La NIOSH viene insistiendo, desde 2005, sobre la necesidad de que los trabajadores de empresas que manipulan dióxido de titanio en polvo (TiO2) tengan condiciones de seguridad diferentes, según se trate de partículas de más de 100 nanómetros o de menos; es decir, recomiendan tratar al $\mathrm{TiO} 2$ nanoparticulado (menos de 100nm) como si fuese un producto diferente del no nanoparticulado. Este producto se utiliza en fábricas de pintura, cosméticos, plásticos, papel, alimentos; desde 1988, la NIOSH lo clasificó como cancerígeno, y su inhalación como la principal vía de penetración al organismo. Estudios en animales han mostrado inflamación pulmonar y tumores provocados tanto por los polvos nanoparticulados como por partículas de mayores tamaños. ${ }^{3}$

Otro ejemplo de la desconsideración por los riesgos a la salud y el medio ambiente de la política de nanotecnología es el de la producción de los nanotubos de carbono, la cual ha crecido exponencialmente en la última década, mientras que su costo por gramo ha pasado de los cien mil dólares a centavos, y se aplica en decenas de ramas económicas (e.g. electrónica, baterías, células solares, plásticos, polímeros, sensores, dispositivos médicos). La NIOSH sugiere un enfoque precautorio, ya que constata que diversos estudios en animales muestran fibrosis pulmonar, inflamación por granulomas y facilidad de migrar hacia la pleura. ${ }^{4}$ Los nanotubos de carbono se comportan de manera muy similar al asbesto que, según la Organización Mundial de la Salud (OMS), provoca, aún hoy, 90 mil muertes por año. ${ }^{5}$ Se sabe que los trabajadores de fábricas que producen o emplean nanotubos de carbono o nanofibras de carbono están expuestos, pero no hay estudios de los efectos en la salud. ${ }^{6} \mathrm{Si}$ esto sucede en Estados Unidos, ¿̨cuáles serán las condiciones de trabajo en los países menos desarrollados, donde también se producen nanotubos de carbono, muchas veces en condiciones de seguridad inferiores?

Una compilación de 1991 a noviembre de 2010 de NanoCeo, un banco de artículos científicos no exhaustivo sobre riesgos relacionados a las nanotecnologías, da el siguiente resultado: 176 artículos científicos relacionados con riesgos de los nanotubos de carbono, 216 con riesgos de las nanopartículas de plata, 81 con las nanopartículas de titanio, 72 con fullerenos y buckyballs, y 49 con puntos cuánticos, todos ellos nanopartículas o nanoestructuras de entre las más comunes en los productos del mercado. Otra institución que reúne información sobre los riesgos asociados con nanopartículas es el Consejo Internacional de Nanotecnología (ICON), que forma parte de la Universidad de Rice en Estados Unidos. De 2000 a 2010, su base de datos registró un aumento en los trabajos científicos sobre los riesgos para la salud humana y el medio ambiente de las nanotecnologías que pasó de alrededor de un centenar en 2005 a más de 550 en 2010 .
Estas compilaciones de artículos científicos dan una clara idea de que hay suficiente información científica para tomar una actitud precautoria.

\section{Se sabe que trabajadores y consumidores están expues- tos a potenciales riesgos de las nanopartículas}

La NIOSH reconoce que los mayores riesgos de las nanopartículas están en polvos en estado sólido, donde éstas se encuentran dispersas o aglomeradas, por ejemplo, en los cosméticos. En un segundo nivel de riesgo están las suspendidas en líquidos, como los nanotubos en agua. En un tercer nivel están las fijas en matrices, como los filmes delgados. Las que, por último, ofrecerían menor riesgo son las incorporadas en nanoestructuras, como aleaciones en metales.

Esta escala de riesgo se asocia, también, a las diferentes maneras en que las nanopartículas pueden ingresar al organismo e interactuar con éste. En términos generales las principales vías de ingreso potencial de nanopartículas al organismo son la inhalación, la ingestión y la penetración a través de la piel. Cuando se trata de productos médicos, también pueden ingresar al organismo vía inyección o por el desprendimiento de nanopartículas utilizadas en implantes. Ciertamente, es necesario tomar en cuenta el caso de accidentes, como incendios o explosiones, que pueden extender los riesgos de las nanopartículas a personas sin protección. ${ }^{8}$

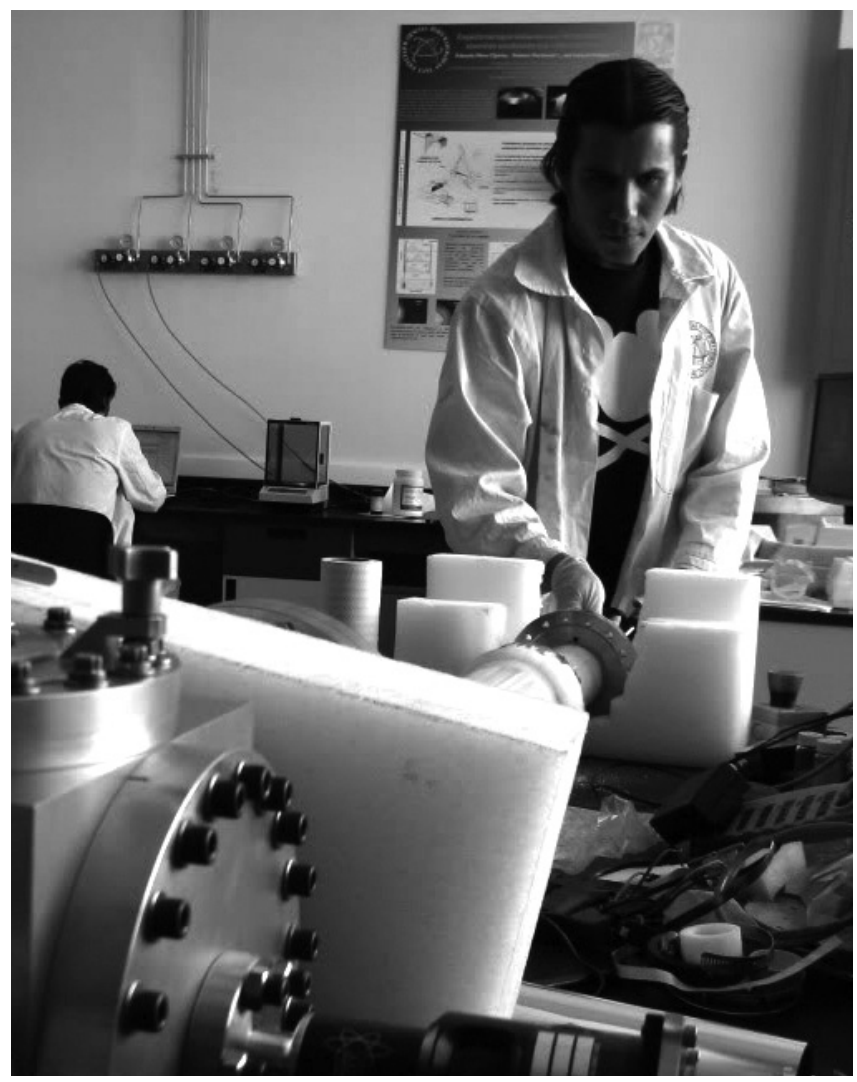


La exposición a las nanopartículas es diferente según su ciclo de vida y la manera como los trabajadores y consumidores se relacionan con éste. Por ejemplo, los propios investigadores son sujeto de riesgo en la etapa de investigación; también los trabajadores de servicio de mantenimiento de los laboratorios, y quienes se encargan de manipular los desechos. Cuando se producen nanomateriales como materia prima en masa, los sujetos directamente expuestos son investigadores, técnicos y operarios de las empresas, así como los encargados de almacenar el producto y los transportistas que llevan la nanomateria prima a las industrias que las requieren. Los obreros de estas industrias también están expuestos y, tal vez, incluso el personal administrativo y de servicio. ${ }^{9}$ Según el tipo de producto y la forma de uso, el consumidor final está expuesto a las nanopartículas. Al final del ciclo de vida y en los procesos de desecho, limpieza y transporte, el medio ambiente puede verse afectado.

Las tres afirmaciones: 1. las nanopartículas tienen efectos toxicológicos nuevos, 2. las nanopartículas son tóxicas in vitro y para diversos organismos vivos en laboratorio, y 3. trabajadores y consumidores están expuestos, son suficientes parar tener un enfoque precautorio. La respuesta de empresas y de muchos científicos es que no se ha comprobado toxicidad en humanos, además de que las nanopartículas no se desprenden de la matriz a la cual están incorporadas, por lo que los estudios in vitro y con otros seres vivos no son representativos del riesgo. Pero se trata de prevenir en lugar de esperar que ocurran implicaciones en la salud humana. Además, el argumento de que no se desprenden de la matriz es relativo. En el caso de los cosméticos, las nanopartículas penetran directamente por la piel; en textiles, el uso, lavado y manipuleo desprende nanopartículas; en alimentos y utensilios de cocina pueden ser absorbidas directamente o por desprendimiento; en dispositivos médicos, interactúan con el organismo y, en todos los casos, los artículos que contienen nanopartículas tienen un ciclo de vida útil que, cuando finaliza, puede llegar a tener efectos inciertos sobre los ecosistemas y las cadenas tróficas.

\footnotetext{
Referencias

${ }^{1}$ FDA (Food and Drug Administration) (2012a), Draft Guidance for Industry: Assessing the Effects of Significant Manufacturing Process Changes, Including Emerging Technologies, on the Safety and Regulatory Status of Food Ingredients and Food Contact Substances, Including Food Ingredients that are Color Additives en http://www.fda.gov/Food/GuidanceComplianceRegulatoryInformation/GuidanceDocuments/ FoodIngredientsandPackaging/ucm300661.htm Visitada Abril 21, 2012; FDA(2012 b), Draft Guidance for Industry: Safety of Nanomaterials in Cosmetic Products en http://www.fda.gov/ Cosmetics/GuidanceComplianceRegulatoryInformation/ GuidanceDocuments/ucm300886.htm; visitada abril 21, 2012.
}

${ }^{2}$ NIOSH (2010), Occupational Exposure to Carbon Nanotubes and Nanofibers. NIOSH Current Intelligence Bulletin Department of Health and Human Services. Centers for Disease Control and Prevention en http://www.cdc.gov/niosh/docket/archive/pdfs/NIOSH-161-A/0161-A-110110-DraftDocument.pdf (noviembre); visitada marzo 15, 2012.

${ }^{3}$ Murashov, Vladimir (2011), Titanium Dioxide: A Changing Paradigm in Occupational Risk Management. The National Institute for Occupational Safety and Health (NIOSH) en http://blogs.cdc.gov/niosh-science-blog/2011/05/tio2/ (9 de mayo); visitada abril 6, 2012.

${ }^{4}$ NIOSH (2010).

${ }^{5}$ En febrero de 2012, dos empresarios de fábricas de asbestos (Eternit) fueron sentenciados a 16 años de cárcel y más de 100 millones de euros en multa por la muerte de más de 2,000 obreros en sus fábricas (Italiano, 2012).

${ }^{6}$ (NIOSH, 2010).

${ }^{7}$ Base de datos ICON (http://icon.rice.edu/) propia fusión de los siguientes nanomateriales: Carbono o Metal u Orgánicos / Polímeros o Semiconductores o de Óxido o Múltiple u Otras / No Especificadas] + Peligro para los siguientes grupos de los trabajadores [Industriales / Trabajadores de Investigación o Los consumidores o la Población en General o los Ecosistemas u Otro / No Especificado] + Artículos de Revistas por Revisar + Ingeniería.

${ }^{8}$ Maynard, Andrew D. et al. (2006), "Safe handling of nanotechnology” en Nature, no. 444, p. 16 (noviembre).

${ }^{9}$ Schulte, Paul et al. (2008), "Occupational Risk Management of Engineered Nanoparticles” en Journal of Occupational and Environmental Hygiene, vol. 5, no. 4, pp, 239-249. 